\title{
Correction: First-Principles Study of Mo Segregation in MoNi(111): Effects of Chemisorbed Atomic Oxygen. Materials 2016, 9, 5
}

\author{
Yanlin Yu ${ }^{1}$, Wei Xiao ${ }^{1,2}$, Jianwei Wang ${ }^{1}$ and Ligen Wang ${ }^{1,3, *}$ \\ 1 General Research Institute for Nonferrous Metals, Beijing 100088, China; yuyanlin_121@163.com (Y.Y.); \\ wxiao@ustb.edu.cn (W.X.); jswjw@sina.com (J.W.) \\ 2 School of Materials Science and Engineering, University of Science and Technology Beijing, \\ Beijing 100083, China \\ 3 Power Environmental Energy Research Institute, Covina, CA 91722, USA \\ * Correspondence: lg_wang1@yahoo.com; Tel.: +86-10-8224-1124; Fax: +86-10-8224-0096
}

Academic Editor: Federico Bella

Received: 28 April 2016; Accepted: 29 April 2016; Published: 11 May 2016

The authors wish to make the following corrections to this manuscript [1]. The published Figure 1 was incorrect of $\mathrm{MoNi}(111)$ alloy systems showing one Mo monomer substituting one $\mathrm{Ni}$ atom in the (a) first; (b) second, (c) third; and (d) fourth nickel layer. However, the mistake does not change any calculated results. For the preciseness of academic logic and the right of academic ethics, the authors must point out their mistake, and correct it. The correct Figure 1 is shown below. And the authors are responsible for these errors, they regret any inconvenience or misunderstanding caused by them.

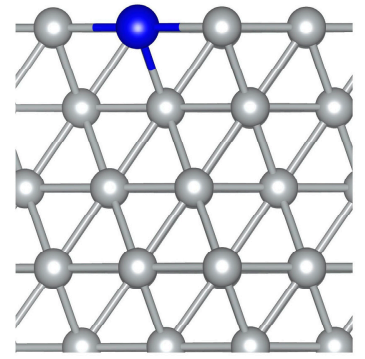

(a)

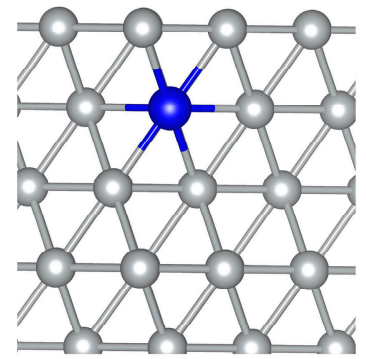

(b)

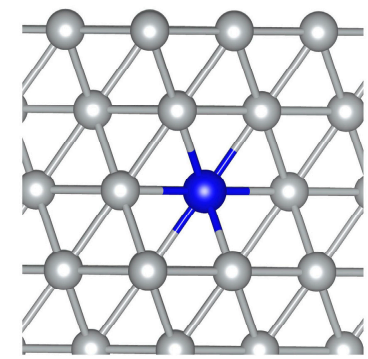

(c)

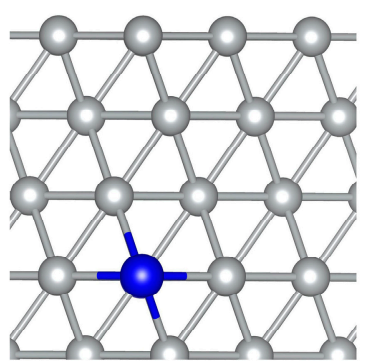

(d)

Figure 1. MoNi(111) alloy systems showing one Mo monomer substituting one Ni atom in the (a) first; (b) second; (c) third; and (d) fourth nickel layer. Only the four top layers are shown. Gray and blue balls represent $\mathrm{Ni}$ and $\mathrm{Mo}$ atoms, respectively.

Conflicts of Interest: The authors declare no conflict of interest.

\section{Reference}

1. Yu, Y.; Xiao, W.; Wang, J.; Wang, L. First-Principles Study of Mo Segregation in MoNi(111): Effects of Chemisorbed Atomic Oxygen. Materials 2016, 9, 5. [CrossRef]

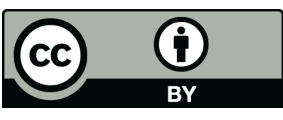

(C) 2016 by the authors; licensee MDPI, Basel, Switzerland. This article is an open access article distributed under the terms and conditions of the Creative Commons Attribution (CC-BY) license (http://creativecommons.org/licenses/by/4.0/). 